\title{
Ankle Ultrasound: Could it Replace MRI in Diagnosis of Different Causes of Chronic Ankle Pain?
}

\author{
ENGY Sh. ELKAYAL, M.D.*; MOHMAD A. MAHMOUD, M.D.*; MOHAMED S. ARAFA, M.D.** and \\ AHMED M. MOHAMED, M.Sc.*
}

The Departments of Radiodiagnosis* and Orthopedics**, Faculty of Medicine, Fayoum University

\begin{abstract}
Background: Chronic ankle pain is considered a diagnostic challenge because of variable causes including traumatic and non-traumatic causes. MRI is considered an excellent method of diagnosis of soft tissue abnormalities around ankle joint. Ultrasonography also can detect normal anatomic structure and assess ligamentous abnormalities, and provide dynamic evaluation of the soft tissues. Ultrasonography is more available, cheap, fast, and safe method of diagnosis.
\end{abstract}

Aim of Study: Was toevaluate the accuracy of both ultrasonography and magnetic resonance imaging in diagnosis of different causes of chronic ankle pain.

Patients and Methods: A comparative study conducted upon attendants referred from orthopedics clinic who complained of ankle pain.

Results: In this study ultrasound successfully diagnosed and characterized 35 out of 40 patients $(85 \%)$ while MRI diagnosed and characterized 36 patients $(87.5 \%)$. MRI is the modality of choice for optimal detection of most of osseous and; soft-tissue disorders of ankle with higher axial resolution and multiplanar capabilities while ultrasound proved to be excellent cost-benefit widely available imaging technique that has high spatial resolution making it helpful tool in diagnosing most of ankle soft tissue disorders with high diagnostic accuracies almost equal to MRI values.

Conclusion: Ultrasonography and MRI are two methods of investigations with the former being used as primary tool of investigation and the latter done to confirm diagnosis and the extent of the lesion especially when surgery is planned.

Key Words: $M R I-U S-A P$.

\section{Introduction}

THE ankle joint is one of the most frequently injured joints with ankle sprains representing most common complaints in orthopedic clinics [1]. Ankle pain can be caused by various traumatic and nontraumatic causes various imaging techniques are available for assessment of ankle pain. Clinicians

\footnotetext{
Correspondence to: Dr. Engy Sh. Elkayal, The Department
}

usually start by conventional plain radiographs being fast, cheap and of good value in assessing osseous structures [2]; however, it is of very limited role in assessing soft tissue components. MRI is considered to be the imaging modality of choice for ankle joint evaluation with advantage of its high spatial resolution, multiplanar capability. MRI is considered very sensitive in detecting most of ankle pathological conditions with early detection of osseous and soft tissue abnormalities. However, the high costs and the relative limited availability of MR imaging systems, as well as the relatively long duration of the examination all are considered disadvantage of MRI examination [3]. US performed with high-resolution linear-array probes has become increasingly important in the assessment of ankle disorders, with advantages of being fast, reliable, of low coast and readily available [ 4]. The aim of the studywas to evaluate the accuracy of both ultrasonography and magnetic resonance imaging in diagnosis of different causes of chronic ankle pain. Findings will be compared with arthroscopy as a gold standard method of evaluation.

\section{Patients and Methods}

A comparative study conducted upon attendants referred from orthopedics clinic who complained of ankle pain. The study was conducted in Radiology \& Imaging Department, Fayoum University Hospital between March 2019 to March 2020.

A total of 40 patients had ultrasonography of ankle joint by musculoskeletal expert according

\footnotetext{
Abbreviations:

MRI: Magnetic Resonance Imaging.

US : Ultrasonography.

AP : Ankle Pain.
} 
to European Society of Musculoskeletal Radiology ( ESSR VI) technique guidelines and MRI of ankle joint. Their age ranged between 18-60 years with mean age 37 years. It included 21 females and 19 males.

Ethics Committee approval and informed consent were obtained. It included all patients who referred from orthopedic clinic complaining of ankle pain. It excluded cognitivedisorder (e.g., mental retardation, dementia). Cardiac pacemakers, older aneurysm clips, new stents or aortic valves, ferromagnetic ocular fragments that could interfere with high-strength magnetic fields.

All patients were subjected to relevant history taking and local examination, ultrasound examination and MRI imaging.

Technique: Ultrasound examinations were performed using linear probes of GE S8 $(12 \mathrm{MHz})$ and had MRI examination: MRI was performed using the following device: TITAN, TOSHIBA 1.5 Tesla. using the following protocol: Axial: T1WI, PD T2WI \& fat suppression sequence. Coronal: T1WI, T2WI \& STIR. Sagittal: T2WI \& STIR. Post contrast study: T1WI (+ Fat sat).

The data and results of both MRI and ultrasound were compared after that with the clinical diagnosis and the gold standard test for each case for example with arthroscopic findings in cases of impingement and osteochondral lesions, open surgical findings in cases of Achilles tear and bursitis or with clinical examination results and therapeutic trials as in cases of tendinitis which received local injection.

\section{Results}

All data manipulation and double entered into Microsoft Access and data analysis was performed using Statistical Package for the Social Sciences ( SPSS) software version 18 under windows 7 . Simple descriptive analysis in the form of numbers and percentages for qualitative data. Sensitivity and specificity test for testing a new test with ROC curve "k2 Receiver Operating Characteristic".

\section{Joint space:}

Fig. (1) illustrates that ultrasound yielded $100 \%$ accuracy in diagnosis of joint space narrowing compared to $95.5 \%$ for MRI.

\section{Joint effusion:}

Table (1) illustrates that $20 \%$ of patients had no joint effusion, and $52.5 \%$ of them show minimal effusion, finally $27.5 \%$ of them had mild to moderate effusion when diagnosed by ultrasound and same finding when diagnosed by MRI. Both yielded $100 \%$ accuracy in detection of joint effusion.

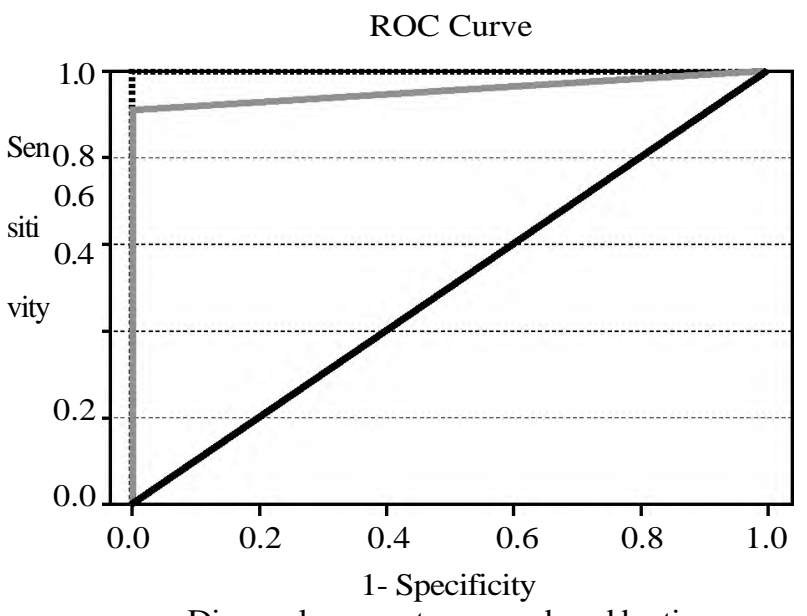

Diagonal segments are produced by ties

\begin{tabular}{|l|}
\hline \multicolumn{2}{|c|}{ Source of the curve } \\
........ Joint $\underline{\text { space.us }}$ \\
Reference Line
\end{tabular}

Fig. (1): Illustrate joint space by different imaging modality.

Table (1): Joint effusion findings by different tools of diagnosis. $p$ $<0.001$.

\begin{tabular}{llcll}
\hline Variables & \multicolumn{2}{c}{$\begin{array}{c}\text { Ultrasound } \\
(\mathrm{n}=40)\end{array}$} & \multicolumn{2}{c}{$\begin{array}{c}\text { MRI } \\
(\mathrm{n}=40)\end{array}$} \\
\cline { 4 - 5 } & $\mathrm{N}$. & $\%$ & $\mathrm{~N}$. & $\%$ \\
\hline No effusion & 8 & 20 & 8 & 20 \\
Minimal & 21 & 52.5 & 21 & 52.5 \\
Mild to moderate & 11 & 27.5 & 11 & 27.5 \\
\hline
\end{tabular}

Bone (osseous) surface:

Table (2) illustrated that $37.5 \%$ of patients show irregularity in bone, $2.5 \%$ had defects, and no patients show marrow edema or infiltration when diagnosed by ultrasound versus $0 \%, 7.5 \%$ and $20 \%$ respectively when diagnosed by MRI, and finally after diagnosed by gold standard it shows only $10 \%$ of patients had bone irregularity, $12.5 \%$ had defects and $20 \%$ marrow edema or infiltration.

Table (2): Bone (osseous) findings by different tools of diagnosis. $p<0.001$.

\begin{tabular}{|c|c|c|c|c|}
\hline \multirow[t]{2}{*}{ Variables } & $\begin{array}{l}\text { HRUS } \\
(n=40)\end{array}$ & $\begin{array}{c}\text { MRI } \\
(n=40)\end{array}$ & \multicolumn{2}{|c|}{$\begin{array}{l}\text { Gold standard } \\
\quad(\mathrm{n}=40)\end{array}$} \\
\hline & $\mathrm{N} . \%$ & N. \% & $\overline{\mathrm{N}}$. & $\%$ \\
\hline Normal & 2460 & 2972. & 23 & 57.5 \\
\hline Irregularity & 1537.50 & 0 & 4 & 10 \\
\hline Defect & 2.5 & 7.5 & 5 & 12.5 \\
\hline Marrow edema/infiltration & 0 & 20 & 8 & 20 \\
\hline
\end{tabular}

Table (3) illustrated sensitivity and specificity of ultrasound and MRI in comparison to gold standard test in diagnosis of bone surface abnor- 
malities proved that ultrasound is better than MRI in diagnosis of early bone surface abnormalities with $91.9 \%$ accuracy while MRI is better for marrow infiltrations.

Table (3): Diagnostic values of U/S versus MRI in diagnosis of bone abnormalities. $p<0.001$.

\begin{tabular}{lccccc}
\hline Varable & Sensitivity Specificity & $\begin{array}{c}+\mathrm{ve} \\
\text { predicted } \\
\text { value }\end{array}$ & $\begin{array}{c}\text {-ve } \\
\text { predicted } \\
\text { value }\end{array}$ & $\begin{array}{c}\text { Accuracy } \\
\text { (AUC) }\end{array}$ \\
\hline HRUS & $88.2 \%$ & $95.1 \%$ & $93.8 \%$ & $91.1 \%$ & $91.9 \%$ \\
MRI & $64.1 \%$ & $100 \%$ & $100 \%$ & $19.3 \%$ & $82.4 \%$ \\
\hline
\end{tabular}

\section{Synovial abnormality:}

Table (4) illustrated that $82.5 \%$ of patients had normal synovium, $15 \%$ of them had thickened and 2 . $5 \%$ of them had ganglion when diagnosed by ultrasound versus $90 \%, 7.5 \%$, and $2.5 \%$ respectively when diagnosed by MRI, and $82.5 \%, 15 \%$, and 2 . $5 \%$ respectively when diagnosed by gold standard test. Ultrasound yielded $100 \%$ accuracy in diagnosis of synovial abnormalities compared to $83.3 \%$ for MRI especially in early synovial disease.

Table (4): Synovial findings by different tools of diagnosis. $p$ $<0.001$

\begin{tabular}{|c|c|c|c|c|c|c|}
\hline \multirow[t]{2}{*}{ Variables } & \multicolumn{2}{|c|}{$\begin{array}{l}\text { HRUS } \\
(n=40)\end{array}$} & \multicolumn{2}{|c|}{$\begin{array}{l}\text { MRI } \\
(\mathrm{n}=40)\end{array}$} & \multicolumn{2}{|c|}{$\begin{array}{l}\text { Gold standard } \\
\quad(\mathrm{n}=40)\end{array}$} \\
\hline & N. & $\%$ & N. & $\%$ & N. & $\%$ \\
\hline Normal & 33 & 82.5 & 36 & 90 & 33 & 82.5 \\
\hline Thickened & 6 & 15 & 3 & 7.5 & 6 & 15 \\
\hline Ganglion & 1 & 2.5 & 1 & 2.5 & 1 & 2.5 \\
\hline
\end{tabular}

Table (5): Illustrated that sensitivity and specificity of ultrasound and MRI in comparison to gold standard test in diagnosis of synovium. $p<0.001$.

\begin{tabular}{lccccc}
\hline Variable & Sensitivity Specificity & $\begin{array}{c}+\mathrm{ve} \\
\text { predicted } \\
\text { value }\end{array}$ & $\begin{array}{c}\text {-ve } \\
\text { predicted } \\
\text { value }\end{array}$ & $\begin{array}{c}\text { Accuracy } \\
\text { (AUC) }\end{array}$ \\
\hline Ultrasound & $100 \%$ & $100 \%$ & $100 \%$ & $100 \%$ & $100 \%$ \\
MRI & $06.1 \%$ & $100 \%$ & $100 \%$ & $94.4 \%$ & $83.3 \%$ \\
\hline
\end{tabular}

Table (6): Illustrated the accuracy of HRU \& MRI in diagnosis causes of ankle pain.s better accuracy of MRI in diagnosis of ankle pain is $87.5 \%$ while accuracy of HRUS is $85 \% . p<0.001$.

\begin{tabular}{lcc}
\hline Variables & Number & Accuracy \\
\hline Diagnosis of causes of ankle pain by HRUS & 35 & $85 \%$ \\
Diagnosis of causes of ankle pain by MRI & 30 & $8 / .5 \%$ \\
\hline Iotal & 40 & $100 \%$ \\
\hline
\end{tabular}

A 21 years old female complaining of Ganglion cyst, presented with right ankle lateral aspect swelling and mild pain, no history of preceding trauma. HRUS was done \& revealed: A welldefined relatively thick walled multilocular cystic structure seen at the anterolateral gutter with deep communication with joint cavity. Fig. (2A,B). MRI revealed: Multilocular cystic structure at the lateral aspect of the ankle joint with fluid signal (low T1 and high T2) Figs. (2,3).

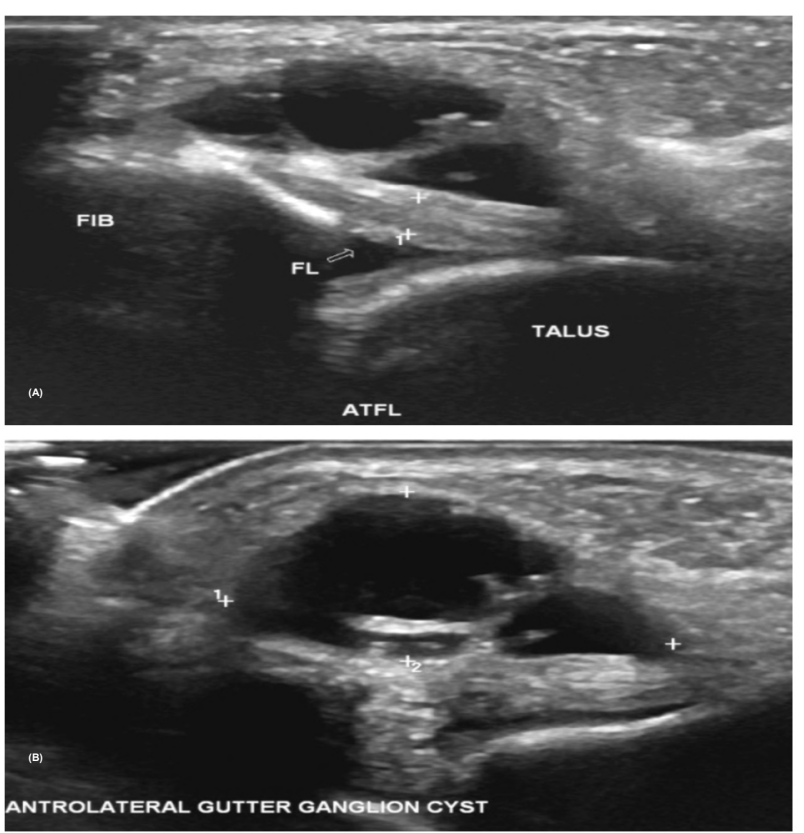

Fig. (2): (A \& B) HRUS examination of the right ankle lateral aspect showing well defined multilocular cystic lesion with clear fluid content. A: The ATFL can be clearly identified (arrow) with fluid seen
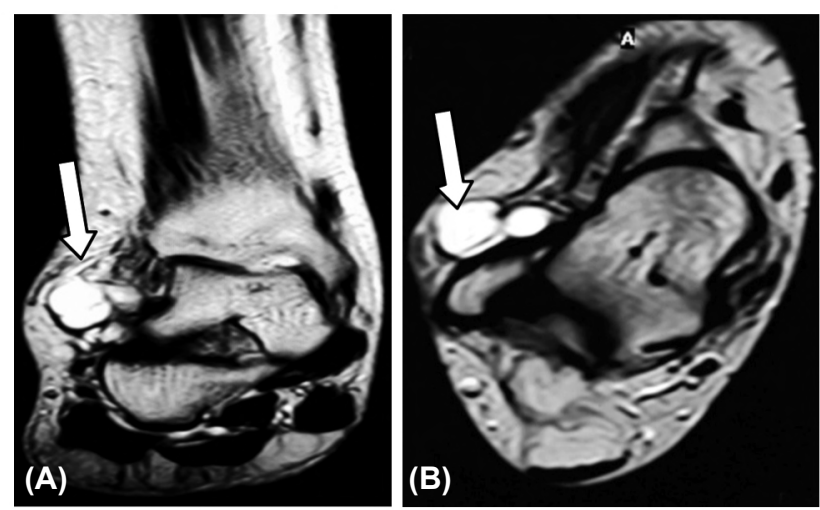

Fig. (3): (A) Coronal T2WI of the right ankle and (B) Axial T2WI of right ankle showing well defined cystic lesion at the lateral aspect with clear fluid within ( low T1 and high T2). (White arrow).

\section{Tendons pathologies:}

Regarding tendons pathology ultrasound yielded overall sensitivity $93.75 \%$ compared to $97.9 \%$ for MRI.

A 50 years old female patient presented with painful ankle after twisting trauma and diagnosed with complete tear of the Achilles tendon and partial thickness tear of the ATFL. Ultrasound examination: Interruption of the Achilles tendon 
about $3 \mathrm{~cm}$ above the calcaneus with gapped retracted edges filled with fluid and calcifications Fig. (4A). Ahypoechoic area within the ATFL denoting partial thickness tear Fig. (4B).

MRI examination: Interruption of the Achilles tendon $4.5 \mathrm{~cm}$ above the calcaneus with gap between two ends is seen filled by intermediate to low T1 and bright T2 signal (hematoma), Fig. (5). Partial tear of the ATFL with fluid collection related to it Fig. (6).

Table (7): Distribution of different tendinous pathological entities diagnosed in this study.

\begin{tabular}{lccc}
\hline Tendon & $\begin{array}{c}\text { No. of all } \\
\text { pathological } \\
\text { entities }\end{array}$ & $\begin{array}{c}\text { No. of pathology } \\
\text { diagnosed } \\
\text { by U/S }\end{array}$ & $\begin{array}{c}\text { No. of pathology } \\
\text { diagnosed by } \\
\text { MRI }\end{array}$ \\
\hline Achilles & 7 & 7 & 7 \\
TA & 3 & 3 & 3 \\
ED & 3 & 3 & 2 \\
Peronii & 4 & 4 & 4 \\
TP & 3 & 2 & 3 \\
FD & 3 & 1 & 3 \\
FHL & 6 & 6 & 6 \\
\hline Total & 29 & 26 & 28 \\
\hline
\end{tabular}

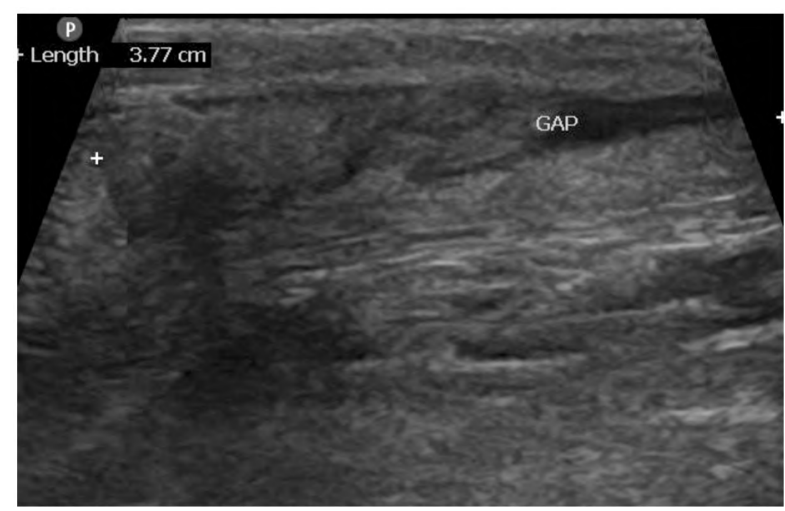

Fig. (4): (A) Longitudinal sonogram of the Achilles tendon showing torn tendon with retracted edges and gap filled with heterogeneous content.

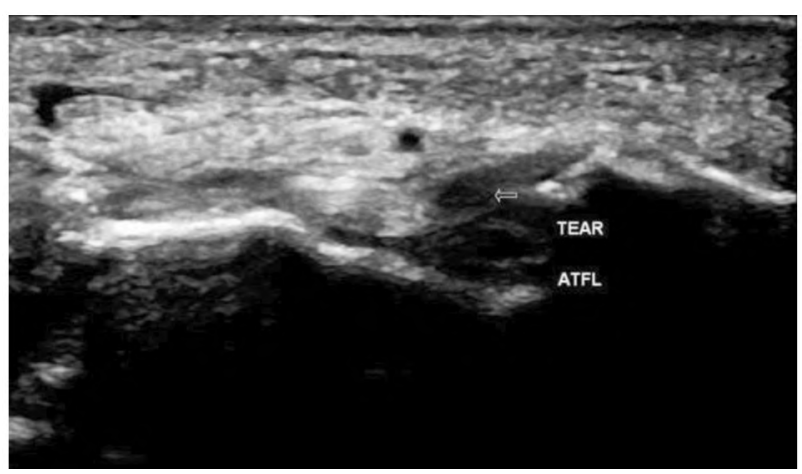

Fig. (4): (B) Axial oblique sonogram of the ATFL showing hypoechoic area within the ligament representing partial thickness tear.

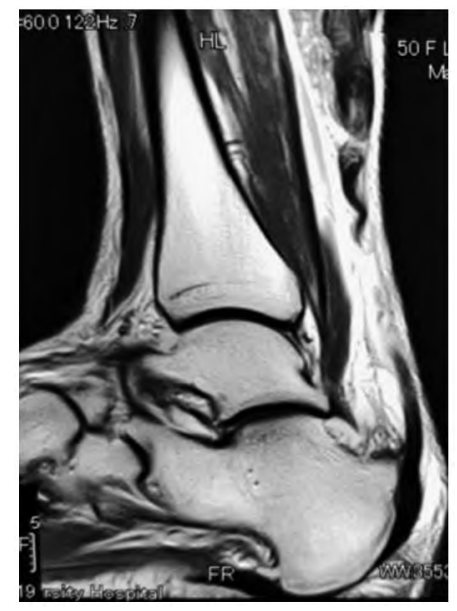

Fig. (5): Complete Achilles tear. Sagittal T2 image showing torn distal Achilles tendon with gap filled with fluid signal and hematoma.

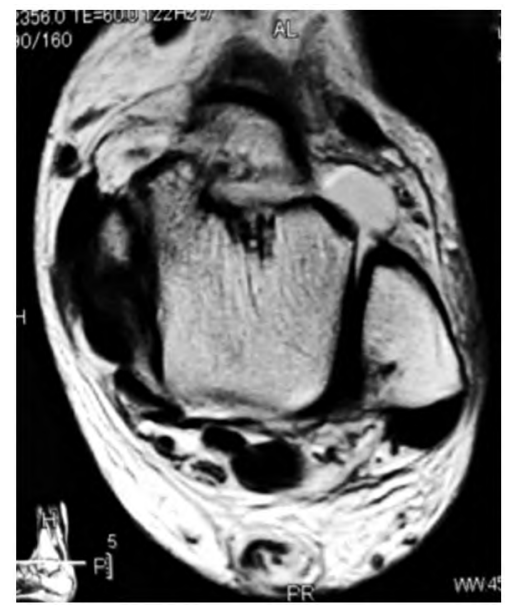

Fig. (6): Axial T2 MRI showing focal discontinuity of the ATFL with fluid signal related to its denoting partial thickness tear.

\section{Ligaments pathologies:}

Ultrasound yielded $100 \%$ sensitivity $92.6 \%$ specificity with diagnostic accuracy $96.3 \%$ compared to $63.4 \%$ sensitivity, $100 \%$ specificity and diagnostic accuracy $80.8 \%$ for MRI (without arthrography) in detection of ligamentous tears.

\section{Ankle Bursae:}

Both ultrasound and MRI reaching 100\% diagnostic accuracy.

\section{Discussion}

In this study we evaluated the diagnostic accuracy of ultrasound in diagnosis of ankle disorders as whole and compare it with the diagnostic accuracy for MRI trying to assess if ultrasound can replace or aid MRI for proper diagnosis or to be used as a primary modality for evaluation and assessing the need for further investigations. 
29 entities of tendon pathologies were diagnosed in this study by all imaging modalities. The most commonly encountered tendon pathology was tenosynovitis followed by complete tendon tears then partial tears.

We found that the most common tendon injury was the Achilles tendon tear, and similar findings were described by Kunwar pal S. et al., 2018 [5]. and (Nevien EL \& Heba K, 2016 as well as Liffen $\mathrm{N}, 2014)[6,7]$ as they reported that the Achilles was the most commonly injured tendon in the body despite being the strongest tendon. Achilles tears were detected in our study in seven cases ranging from partial tear to complete gapped tears. Site of pathological findings is typically zone of relative avascularity $2-6 \mathrm{~cm}$ from the tendon insertion and patients being nearly of middle edge group (40-65 years); results also agrees with (Klauser AS et al., 2013) [8] and (Liffen N, 2014).

Moreover, we found that ultrasound was successfully capable of detecting and classifying all Achilles tendon injuries identified by MRI (yielding $100 \%$ sensitivity). This agrees with Nevien EL \& Heba K, 2016 [6,7] who stated that U/S and MRI had $100 \%$ sensitivity in diagnosing and classifying Achilles tears compared to operative findings. Also, with Hartgerink P, Fessell DP et al., 2001 [9] who reported results of US in characterizing Achilles tendon tears were as follows: Sensitivity, 100\%; specificity, $83 \%$; accuracy, $92 \%$.

Regarding all tendon's pathology ultrasound yielded overall sensitivity $93.75 \%$ compared to 97.9\% for MRI in agreement with Nevien EL and Heba K, 2016 [6,7], reporting both US and MRI were very sensitive in diagnosing tendons pathology ( both had $100 \%$ sensitivity).

14 cases of ligamentous injury were diagnosed in our study representing 35\% of total cases. Most of ligamentous tears were seen involving the ATFL ( 13 case) with only one case of medial collateral ( deltoid) ligament tear. This matches with previous studies as Nevien EL \& Heba K, 2016 [6,7] as well as Margetic P et al., 2009 [10] reporting the ATFL as the most frequently injured ankle ligament. Also, Cheng Y et al., 2014 [11] reported that the AFTL is the most frequently injured ligament among the lateral collateral ligaments followed by the CFL while the PTFL ligament tears requiring far more severe injuries.

Among the 13 cases of ATFL abnormalities three cases presented in ankle pain and swelling following twisting trauma (ankle sprains); ultrasound examination detected partial thickness tear of the ATFL. MRI showed the same findings yet sometimes requested thin cuts images.

In our study ultrasound reached $100 \%$ sensitivity in detecting ligamentous injury. Similar to results achieved by (Cheng Y et al., 2014) who stated $93 \%$ sensitivity of ultrasound in detecting ATFL tears. Also, Nevien EL \& Heba K, 2016 [6,7] and Margetic P et al., 2009 [10] reported 100\% sensitivity of ultrasound in assessing ATFL tears compared to MRI and operative findings.

However, these results are against relatively old studies like D'Emre, 1996 [12] how reported that MRI was superior to ultrasound diagnosing ankle lateral collateral ligament injury. This could be attributed to the development of high frequency probes which gained much improvement of resolution and helped visualization of complex small structures of the ankle.

Thus, after inversion ankle injury, visualization of an intact ATFL virtually excludes rupture of any of the lateral collateral ligaments denoting it is a good negative test; which matched results by Martolini C and Bianchi S, 2007 [13].

In our study 9 cases presented with pain and tenderness at the anterolateral gutter and were clinically diagnosed as anterolateral impingement; all were examined by ultrasound and MRI assessing the anterolateral gutter as well as the ATFL with results compared to ankle arthroscopy. Ultrasound proven to be superior to the MRI in cases of anterolateral impingement by diagnosing typical impingement (synovial mass at the anterolateral gutter with or without extrusion and fluid within the recess) in 8 cases with $(88.9 \%)$ while the other case could reveal only thickened ATFL compared to the contralateral healthy joint. On the other hand, ultrasound wrongfully showed thickened ATFL in three cases which proven to be normal in MR and arthroscopic evaluation.

Among the nine impingement cases MRI could only diagnosis five cases $(55.55 \%)$.

In our study as regard all ATFL related pathologies ultrasound yielded $100 \%$ sensitivity $92.6 \%$ specificity with diagnostic accuracy $96.3 \%$ compared to $63.4 \%$ sensitivity, $100 \%$ specificity and diagnostic accuracy $80.8 \%$ for MRI (without arthrography).

This unveiled the fact that ultrasound could be of more value in cases of anterolateral impingement; similar results were reported by McCarthy CL et al., 2008 [14] reporting ultrasound examina- 
tion detected a soft tissue mass in the antero-lateral gutter consistent with a synovitic lesion in all 8 out of 8 footballers with a clinical diagnosis of anterolateral impingement yielding sensitivity ( 100\%). In 7 patients, the lesion measured more than $10 \mathrm{~mm}$ in its maximum dimension. In these cases, the synovitic lesion could be seen to extrude or bulge anteriorly from the antero-lateral gutter with manual compression of the distal fibula against the tibia. Also, Cochet $\mathrm{H}$ et al., 2010 [15] reported diagnostic performance of US imaging versus arthrography before and after intra-articular injection of contrast agent (CT arthrography), sensitivity and specificity were 77 and $55 \%$, respectively, before opacification and 85 and $71 \%$, respectively, after opacification.

A single case of medial collateral ligament tear was encountered in our study in a male following severe traumatic eversion injury. Ultrasound examination showed disruption of the superficial layers of the medial collateral ligament with hematoma formation. MRI showed the same results as well a bone marrow edema; thus, both U/S and MRI yielded $100 \%$ sensitivity in medial collateral ligaments injury.

In our study ultrasound showed $100 \%$ sensitivity in detection of ankle effusion detected by MRI, similar results were also reported by Nevien EL \& Heba K, 2016 [6,7] reporting 100\% sensitivity and specificity of ankle ultrasound in detection of ankle effusion. Yet contradicting with Jacobson et al., 1998 [16] and Fessell DP and Van Holsbeeck MT, 1999 [17] who concluded that MRI is more sensitive than ultrasonography in detection of ankle effusion; MRI could detect intra-articular fluid of $1 \mathrm{ml}$ while sonography could reproducibly detect $2 \mathrm{ml}$ of fluid, this again may be attributed to the recent development of high resolution US probes and their impact on improving US spatial resolution.

Seven cases of synovial abnormality were detected in our study; six cases of synovial thickening could be detected by ultrasound while MRI could only detect synovial thickening in three cases. A case of synovial ganglion was easily diagnosed by both ultrasound and MRI. Ultrasound reached $100 \%$ diagnostic accuracy in synovial abnormalities compared to $83.3 \%$ for MRI.

This proves that ultrasound is sensitive for early detection of synovial diseases matching with previous studies stating that ultrasound has been shown to be very sensitive in assessment of synovitis. Grassi W, 2003; Kane D et al. 2003, [18,19] stated ultrasound is even more sensitive than clinical examination in determining synovitis.

Brown AK et al., 2008 [20] also reported that RA patients who were judged by their consultant rheumatologist to be in remission had significant evidence of active inflammation on US. This ongoing subclinical inflammation can lead to radiographic progression.

Yet this disagrees with many other studies who reported that MRI is the gold standard for evaluation of synovial abnormalities like Shaloo B and Peter P, 2015 [21], Hoving JL et al., 2004 [22] and Marcin S et al., 2001 [23]. This can be attributed to many factors like the fact that the majority of synovial thickening in our cases was due to osteoarthritic rather than inflammatory synovitis and the use of routine MRI sequences with no sequences dedicated for synovial pathology (eg gradient echo) or the dynamic contrast enhanced MRI to detect synovial activity.

Finally, many of recent literature like Patil $\mathrm{P}$ \& Dasgupta B, 2012 [24] are focusing on the rapidly evolving role of US for synovial activity especially in RA patient and that the use of power Doppler examination is approaching diagnostic levels for MRI.

Regarding bone surface ulceration our study included five cases representing $12.5 \%$ of the cases. One case of the ultrasound examination showed focal marked talar cartilage thinning out missed by MRI; further arthroscopic examination showed talar surface chondral ulceration.

In the other four cases of the arthroscopically proven osteochondral ulceration, MRI successfully diagnosed three cases (60\%) while ultrasound could only detect bone surface irregularities and irregular overlying cartilage.

Another case in our study presented by chronic ankle pain ultrasound could detect expanded calcaneus bone with marked cortical irregularities and interior echoes; MRI revealed calcaneal aneurysmal bone cyst which was histologically proven. This unveils the fact that MRI is much more superior to ultrasound in bone marrow lesions.

In our study three cases of posterior ankle joint pain clinically diagnosed as posterior impingement were successfully diagnosed by ultrasound and MRI thus yielding $100 \%$ sensitivity. Both could detect posterior joint recess effusion, synovial thickening, soft tissue edema as well as FHL tenosynovitis; findings which all are typical in posterior impingement syndrome. 
Ultrasound and MRI were also capable of detecting the causative factor in all cases such as elongated posterior talar process (Stieda's process) noted in two of the cases and a case of posterior calcaneal spur. However, MRI and conventional radiographs appear to detect osseous causes of posterior impingement more easily. Robinson $\mathrm{P}$ and White LM, 2002 [25] stated that MR imaging clearly depicts bony and soft tissue abnormalities associated with PAI syndrome, and that the role of ultrasonography is limited as it may only detect associated soft tissue injuries.

Our study included a 50 years old male presented with old extensive lower limb DVT with involvement of the posterior tibial veins. The thrombosed posterior tibial vein could be seen by ultrasound of enlarged caliper and indenting the posterior tibial nerve at the tarsal tunnel. MRI evaluation showed edematous sinus tarsi. The patient was diagnosed to have sinus tarsi syndrome caused by the DVT.

\section{Conclusion:}

Ultrasonography and MRI are two methods of investigation with the former being used as primary tool of investigation and the latter done to confirm diagnosis and the extent of the lesion especially when surgery is planned.

MRI is the modality of choice for optimal detection of most of osseous and soft-tissue disorders of ankle with higher axial resolution and multiplanar capabilities.

Ultrasound proved to be excellent cost benefit widely available imaging technique that has high spatial resolution making it helpful tool in diagnosing most of ankle soft tissue disorders with high diagnostic accuracies almost equal to MRI values. Ultrasound also proved to be very valuable in assessment of dynamic disorders like impingement and entrapment syndromes. Another advantage to ultrasound is the ability to perform US guided therapeutic injections.

Ultrasound examination is also valuable in assessing ankle disorders when metallic artifacts would limit imaging with MRI or CT.

\section{References}

1- CRAIG C.Y.: Ankle sprain, Medscape Website, Jan. 03, 2016

2- HANS P. and KARL G.: Diagnosis and treatment of acute ankle injuries: Development of an evidence-based algorithm, Orthop. Rev. (Pavia), Jan. 2; 4 (1): e5, 2012.
3- MASCIOCCHI C. and BARILE A.: Imaging of musculoskeletal MRI: Dedicated systems. Eur. Radiol., 10: 250$5,2000$.

4- LUCA M. and DAVIDE O.: Dynamic high-resolution US of ankle and midfoot ligaments: normal anatomic structure and imaging technique RadioGraphics, 35, pp. 164-78, 2015.

5- KUNWARPAL S., CHUNI L., KAMIESH and AVTAR S. : Comparison of high-resolution ultrasonography with clinical findings in patients with ankle pain. Journal of Ultrasonography, 2018.

6- NEVIEN EL L. and HEBA K.: High resolution ultrasonography and magnetic resonance imaging in the evaluation of tendino-ligamentous injuries around ankle joint, The Egyptian Journal of Radiology and Nuclear Medicine, Volume 47, Issue 2, June, Pages 543-55, 2016.

7- LIFFEN N.: Achilles tendon diagnostic ultrasound examination: A locally designed protocol and audit. Int. Musculoskeletal. Med., 36 (1): 1-12, 2014.

8- KLAUSER A.S. and MIYAMOTO H.: Achilles Tendon assessed with sonoelastography, RSNA radiol, June, Volume 267, Issue 3, p: 837-42, 2013.

9- HARTGERINK P. and FESSELL D.P.: Full- versus partialthickness Achilles tendon tears: Sonographic accuracy and characterization in 26 cases with surgical correlation. Radiology, 220: 406-12, 2001.

10- MARGETIC P. and SALAJ M.: The Value of Ultrasound in Acute Ankle Injury: Comparison with MR. European Journal of Trauma and Emergency Surgery, Volume 35, Issue 2, pp. 141-6, 2009.

11- CHENG Y. and CAI Y.: Value of ultrasonography for detecting chronic injury of the lateral ligaments of the ankle joint compared with ultrasonography findings, $\mathrm{Br}$. J. Radiol., Jan., 87 (1033): 20130406, 2014.

12- D'ERME M.: Lesions of the collateral ligaments of the ankle. Diagnosis and follow-up with magnetic resonance and ultrasonography. Radiol. Med. Torino., 91: 705-12, 1996.

13- MARTINOLI C. and BIANCHI S.: Ultrasound of the Musculoskeletal System, p.773-834, 2007.

14- McCARTHY C.L. and WILSON D.J.: Anterolateral ankle impingement: Findings and diagnostic accuracy with ultrasound imaging, Skeletal Radiol., 37: 209-16, 2008.

15- COCHET H. and PELÉ E.: Anterolateral Ankle Impingement: Diagnostic Performance of MDCT Arthrography and Sonography, AJR June, Volume 194, Number 6, P: $1575-80,2010$.

16- JACOBSON J.A. and ANDRESEN R.: Detection of ankle effusions: Comparison study in cadavers using radiography, sonography, and MR imaging, AJR Am. J. Roentgenol., May, 170 (5): 1231-8, 1998.

17- FESSELL D.P. and VAN HOLSBEECK M.T.: Foot and ankle sonography. Radiol Clin. North Am., 37: 831-58, 1999.

18- GRASSI W.: Clinical evaluation versus ultrasonography: Who is the winner? J. Rheumatol., May, 30 (5): P: 908 9, 2003.

19- KANE D. and BALINT P.V.: Ultrasonography is superior 
of knee joint effusion in rheumatoid arthritis. J. Rheumatol., 30: 966-71, 2003.

20- BROWN A.K. and CONAGHAN P.G.: An explanation for the apparent dissociation between clinical remission and continued structural deterioration in rheumatoid arthritis. Arthritis Rheum., 58: 2958-67, 2008.

21- SHALOO B. and PETER P.: The Role of Power Doppler Ultrasonography as Disease Activity Marker in Rheumatoid Arthritis, Hindawi Publishing Corporation Disease Markers Volume, Article ID 325909, 9 pages (1-9), 2015.

22- HOVING J.L. and BUCHBINDER R.: A Comparison of Magnetic Resonance Imaging, Sonography, and Radiography of the Hand in Patients with Early Rheumatoid Arthritis, J. Rheumatol., 31, (4): 663-75, 2004.
23- MARCIN S. and MICHEL C.P.: Power doppler ultrasonography for assessment of synovitis in the metacarpophalangeal joints of patients with rheumatoid arthritis: A comparison with dynamic magnetic resonance imaging, Arthritis \& Rheumatism Vol. 44, No. 9, September, p 2018-23, 2001.

24- PATIL P. and DASGUPTA B.: Role of diagnostic ultrasound in the assessment of musculoskeletal diseases. Therapeutic advances in musculoskeletal disease 10/2012;4 (5): 341-55, 2012.

25- ROBINSON P. and WHITE L.M.: Soft tissue and osseous impingement syndromes of the ankle. Role of imaging in diagnosis and management. Radiographics, 22: 1457-71, 2002 .

\title{
الموجات فوق الصوتية للكاحل:

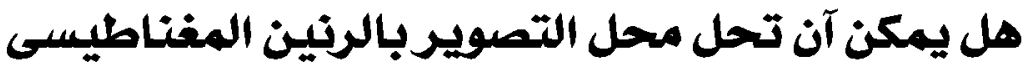

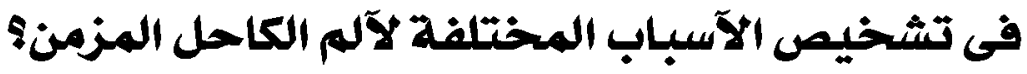

\author{
تعتبر آلام الكاحل من آكثر الآعراض شيوعاً ويتم تقيمها مبدآياً عن طريق الآشعة السينية ولكن يقتصر تقيمها على كسود العظام. يعتبر

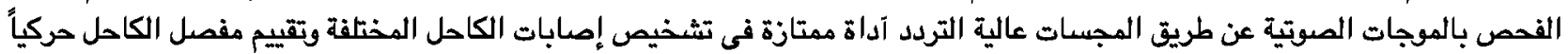

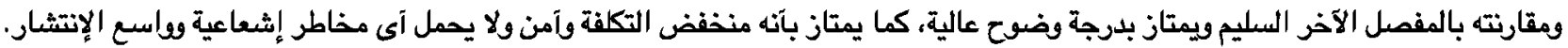

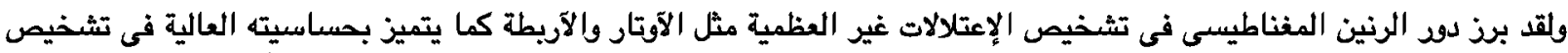

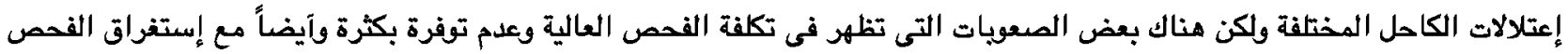 \\ مدة طويلة لذالك ظهرت الحاجة لآداة تشخيصية جديدة. \\ وكان الهلف من الدراسة مقارنة بين الموجات الصوتية عالية الجودة والتصوير بالرنين المغناطيسى فى تقييم الإعتلالات العضلية المسبية \\ لآلم الكاحل. \\ وشملت هذه الدراسة آريعين مريضاً يعانون من آلام الكاحل وقد تم آخذ تاريخ مرضى مفصل من كل منهم مع الفحص الإكلينيكى وتم \\ تصويرهم بالموجات الصوتية والرنين المغناطيسى للكاحل المتضرد. \\ ولقد آَثتبت الدراسة آن دقة الموجات الصوتية في تشخيص آمراض الكاحل المختلة هى هـ٪ ودقة الرنين المغناطيسى فى تثخيص

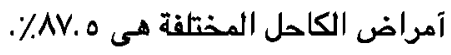

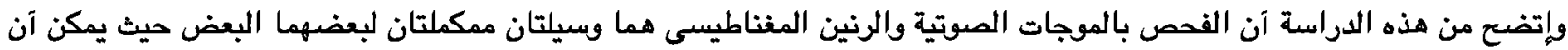

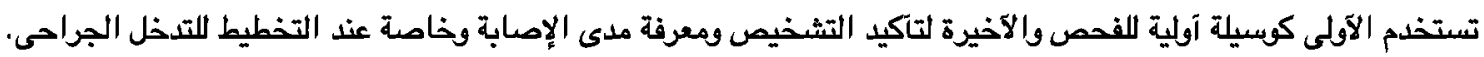

